\title{
Efficacy and safety of adalimumab in the treatment of non-infectious uveitis: a meta-analysis and systematic review
}

This article was published in the following Dove Press journal:

Drug Design, Development and Therapy

\author{
Shuai Ming ${ }^{1,2}$ \\ Kunpeng $\mathrm{Xie}^{1,2}$ \\ Huijuan $\mathrm{He}^{1,2}$ \\ Ya Li ${ }^{1,2}$ \\ Bo Lei ${ }^{1-3}$
}

'Clinical Research Center, Henan Eye Institute, Henan Eye Hospital, ${ }^{2}$ Department of Ophthalmology, Henan Provincial People's Hospital, ${ }^{3}$ Department of Ophthalmology, People's Hospital of Zhengzhou University, Zhengzhou, China
Correspondence: Bo Lei Henan Provincial People's Hospital, Henan Eye Institute, Henan Eye Hospital, 7 Weiwu Road, Zhengzhou 450003, China Email bolei99@I26.com
Objective: To summarize updated evidences on the efficacy and safety of adalimumab (ADA) in the treatment of patients with non-infectious uveitis.

Patients and methods: A systematic search between January 2000 and September 2017 was conducted using PubMed, Embase, and Cochrane libraries. We investigated control of inflammation, improvement of visual acuity (VA), corticosteroid-sparing effect, and adverse events (AEs) or serious adverse events.

Results: Three randomized clinical trials (RCTs) and 20 non-RCTs were included and analyzed. The pooled proportions of inflammation control were $74 \%$ (95\% CI 64\%-82\%) and 79\% (95\% CI $69 \%-87 \%$ ) in groups of $\leq 6$ - and $\geq 12$-months follow-up durations. No significant difference was found between the two groups $\left(\chi^{2}=0.920, p=0.337\right)$. Analysis of subgroups classified by degree of being treatment-naïve for anti-TNF $\alpha$ agents showed the inflammation control reached a high of $87 \%$ (95\% CI 80\%-92\%) when subjects were "almost naïve" to anti-TNF $\alpha$ before ADA treatment. VA was improved by three or more lines in $41.3 \%(52 / 126)$ eyes, and was equal to or better than the baseline in $88.8 \%$ (142/160) eyes. Corticosteroid sparing was observed in $82.0 \%(91 / 111)$ of the patients; among them, $48.8 \%(40 / 82)$ discontinued use of corticosteroid completely. Minor drug-related adverse events were reported. The treatment effects of ADA were generally consistent in the three RCTs, and ADA reduced the risk of treatment failure by $43 \%-75 \%$.

Conclusion: The current review provided evidences that ADA might be a promising choice in reducing inflammatory activity, gaining VA, and sparing corticosteroid use with minor AEs when applied in treating non-infectious uveitis.

Keywords: adalimumab, non-infectious uveitis, anti-TNF $\alpha$, uveitis treatment

\section{Introduction}

Non-infectious uveitis, associated with an underlying, systemic, vision-threatening disease, is characterized by inflammation in the uveal tract. ${ }^{1-3}$ Currently, the mainstay therapy of uveitis is corticosteroids. However, some types of non-infectious uveitis, especially those that are refractory, do not respond well to corticosteroid treatment. Adalimumab (ADA) is a widely used full-length human monoclonal antibody that targets tumor necrosis factor alpha $(\mathrm{TNF} \alpha)^{4,5}$ - a pro-inflammatory cytokine involved in intraocular inflammation. Emerging evidences have shown that ADA is moderately or highly efficacious in suppressing uveitis, allowing a significant reduction in the mean immunosuppression load and the mean corticosteroid dose..$^{6-17}$ Moreover, some expert consensus statements have recommended ADA as the first-choice anti-TNF agent for the management of uveitis secondary to juvenile idiopathic arthritis (JIA), ankylosing 
spondylitis, and uveitis of diverse etiologies, such as sarcoidosis, Behçet's disease, Vogt-Koyanagi-Harada disease, ${ }^{18,19}$ and even as rescue therapy ${ }^{20}$ after the failure of other anti-TNF $\alpha$ agents. Although approved for the treatment of non-infectious uveitis in adults in the USA, Japan, and some countries in Europe (EU), worldwide, ADA is still not yet used widely in the treatment of non-infectious uveitis.

We herein undertook a meta-analysis and review aiming at systematically evaluating the efficacy, safety, and tolerability of ADA in the treatment of non-infectious uveitis.

\section{Patients and methods Eligibility criteria}

We defined the inclusion criteria as follows: 1) non-infectious autoimmune uveitis-related studies; 2) patients who were on a chronic course under immunosuppressive therapy and systemic steroid treatment previously for at least 3 months and showed refractory uveitis; 3 ) the uveitis inflammatory activity grading was described according to the Standardization of Uveitis Nomenclature (SUN) working-group criteria; ${ }^{21} 4$ ) at least a 3-month median follow-up duration; and 5) studies with at least five patients to avoid a positive report bias.

\section{Outcome measurement}

1) Control of inflammation was defined by the anterior chamber cells and/or vitreous haze decreasing by two levels or to grade $0.5+$ or 0 , respectively, according to the SUN criteria and National Eye Institute system criteria adopted by SUN in at least one eye. Besides, some studies require structural complications or comorbidities, such as cystoid macular edema (CME), vasculitis, and papillary edema, to be confirmed by fluorescein angiography (FA) or optical coherence tomography (OCT) examinations. For a comprehensive analysis, we included all of these studies.

2) Controlled visual acuity (VA), according to the SUN criteria, ${ }^{21}$ was defined as a doubling of the visual angle (converted into logMAR format) in the involved eye from baseline corresponding to three lines on a decimal scale with a logarithmic chart. Further, we collected information of VA maintaining stable or improving at least one line.

3) Corticosteroid sparing was defined as a significant decrease, by $\geq 50 \%$, for example, or cessation of daily corticosteroid use since the day anti-TNF treatment was initiated.

4) Time to treatment failure was defined as the time up to when SUN-cell-activity score (anterior chamber cell/ vitreous haze grade) had worsened (a two-grade increase) or had not improved (decrease to $\leq 0.5+$ ). Studies that adopted multiple endpoints, including increase of vitreous haze/anterior chamber cells and new active lesions and decrease in best-corrected VA (BCVA), were also discussed in our study.

5) Safety was assessed by the occurrence of adverse effects (AEs). Serious adverse effects (SAEs) were specified as ADA treatment interruption, hospitalization, or death.

\section{Search strategy}

A relevant literature search was conducted using the electronic databases of Medline, Embase, and the Cochrane Library from January 2000 to September 2017, with language restriction of only articles in English. The terms/key words were "uveitis" or "iridocyclitis" crossed with "anti-TNF $\alpha$ " or "anti-tumor necrosis factor alpha" or "anti TNF alpha" or "TNF alpha inhibitors" and "adalimumab". Uveitis was not restricted by the words of "chronic", "non-infectious", and "autoimmune" to enlarge the number of hits in the literature to be screened. Study types were not limited to clinical trials. Thus, uncontrolled case series, nonrandomized, retrospective clinical studies, and prospective open-label trials were also included to provide more evidences related to the effectiveness of ADA in uveitis.

\section{Study selection and data collection}

Two reviewers (Shuai Ming and Kunpeng Xie) screened the titles and abstracts of the searched studies independently to determine their relevance to this study. Full-text articles were assessed for eligibility according to the eligibility criteria. Evaluations of methodological quality and risk of bias were undertaken. Discussions were held resolve any disagreement in the procedure until a consensus was reached. A standard form was applied for information collection from the selected articles. The information captured included: study design type, number of patients, age and gender statistics, duration of follow-up, and definitions of outcomes and results. If the same registered trial appeared on sequential or multiple publications, the data from the most recent or comprehensive publication was included.

\section{Data synthesis and analysis}

An evaluation of outcomes was done per patient, with the exception of VA which was mainly pooled per eye. Description of outcomes was graded dichotomously by "yes" or "no" responses. With different analytical methods, studies reported their outcomes, either based on time points (eg, 3, 6 , or 12 months) or based on the median follow-up durations. 
For the analysis of the pooled proportion of controlled inflammatory activity, extracted data were categorized into two groups of "6 months or less" and "12 months or more" and this grouping helped explain the short-term and relatively long-term efficacy of ADA on uveitis, respectively.

The strength of evidence of non-randomized clinical trials (RCTs) was rated using a scale from the Scottish Intercollegiate Guideline Network (SIGN). ${ }^{22}$ The modified Jadad Scale was used to assess the methodological quality and risk of bias of RCTs. All assessments were independently done by two investigators (Shuai Ming and Kunpeng Xie).

The meta-analysis was conducted in accordance with preferred reporting items for systematic reviews and metaanalyses guidelines, in principle. ${ }^{23}$ The pooled proportions (controlled uveitis activity) and 95\% CIs were realized by the "Metaprop" program package in R 3.2.0. Study homogeneity was investigated using $I^{2}$ statistic to quantify the percentage of variation across studies. A random-effects model (DerSimonian-Laird method) was used to present the pooled results if the $I^{2}>50 \%$ and $p<0.1$. Otherwise, a fixed-effects model (Mantel-Haenszel method) was used. Subgroup analysis was conducted if obvious heterogeneity existed. The difference in groups of pooled proportions was statistically significant when $p<0.05$. A meta-analysis of clinical trials was done with a similar statistical procedure, if possible; otherwise, a systematic review was conducted.

\section{Results \\ Selection of studies}

A total of 323 possible relevant articles were returned from a computerized search of various databases; of these, 247 were excluded after scanning the titles and abstracts. After full-text scrutiny of the remaining 76 articles, we included 35 studies which were specific to the research questions and contained useful information. Thereafter, 12 potentially eligible articles were removed because they did not meet our inclusion criteria or their data type could not be synthesized together. Finally, 23 studies were retained for the meta-analysis, with 20 nonRCTs and three RCTs. The systemic procedure and detailed exclusion criteria in each step are shown in Figure 1.

\section{Characteristics of included studies}

Table 1 shows the summary characteristics of the 20 selected non-RCTs studies. ${ }^{9,10,12,20,24-39}$ All of these studies were observational, nonrandomized case series from EU or the US. All studies had a median or mean follow-up duration of more than 6 months, with one exception. ${ }^{12}$ In all studies, ADA was administered at 40 or $20 \mathrm{mg} / \mathrm{m}^{2}$ - depending on

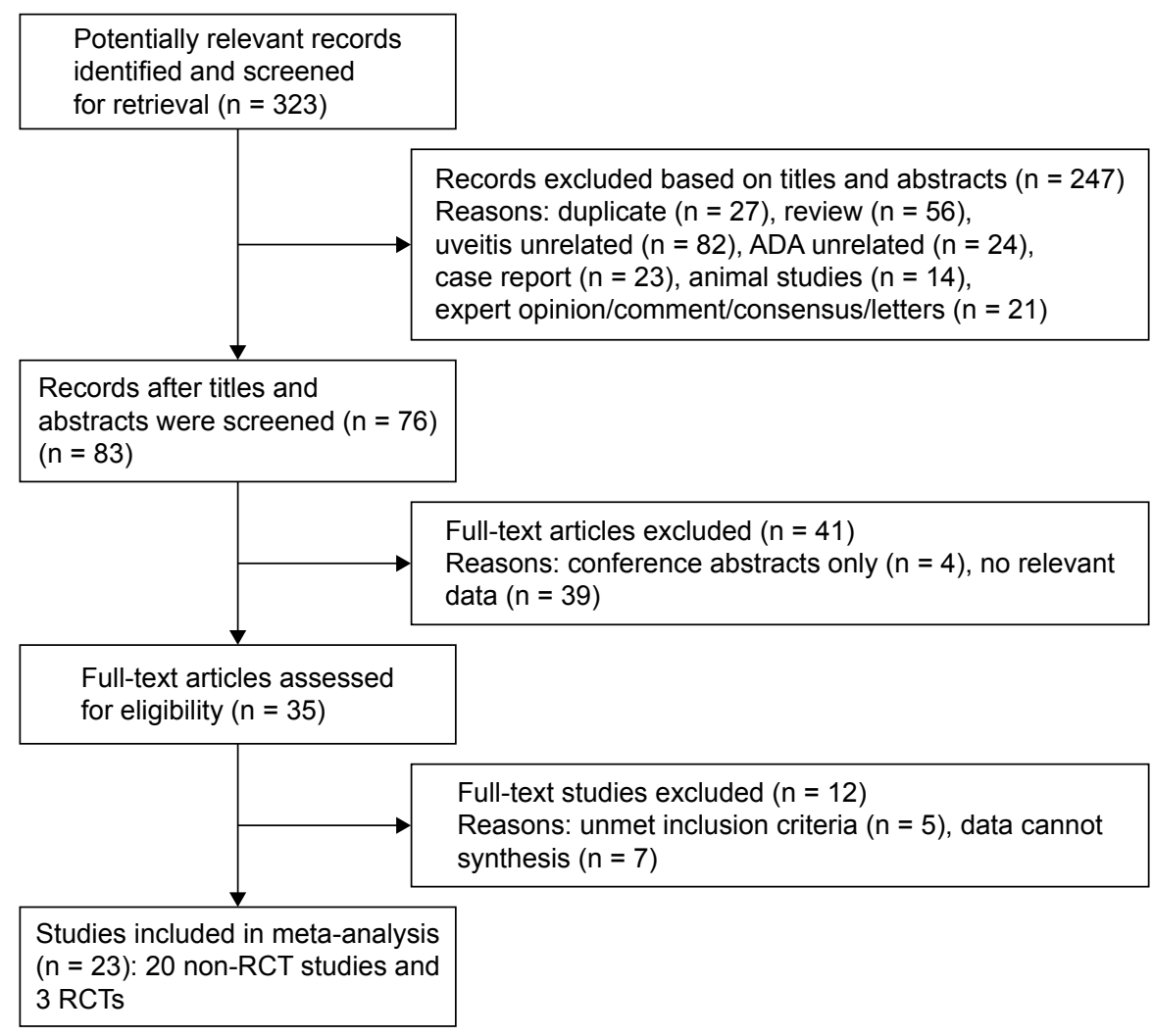

Figure I Flow diagram demonstrating the process of study identification. Abbreviations: ADA, adalimumab; RCT, randomized clinical trial. 


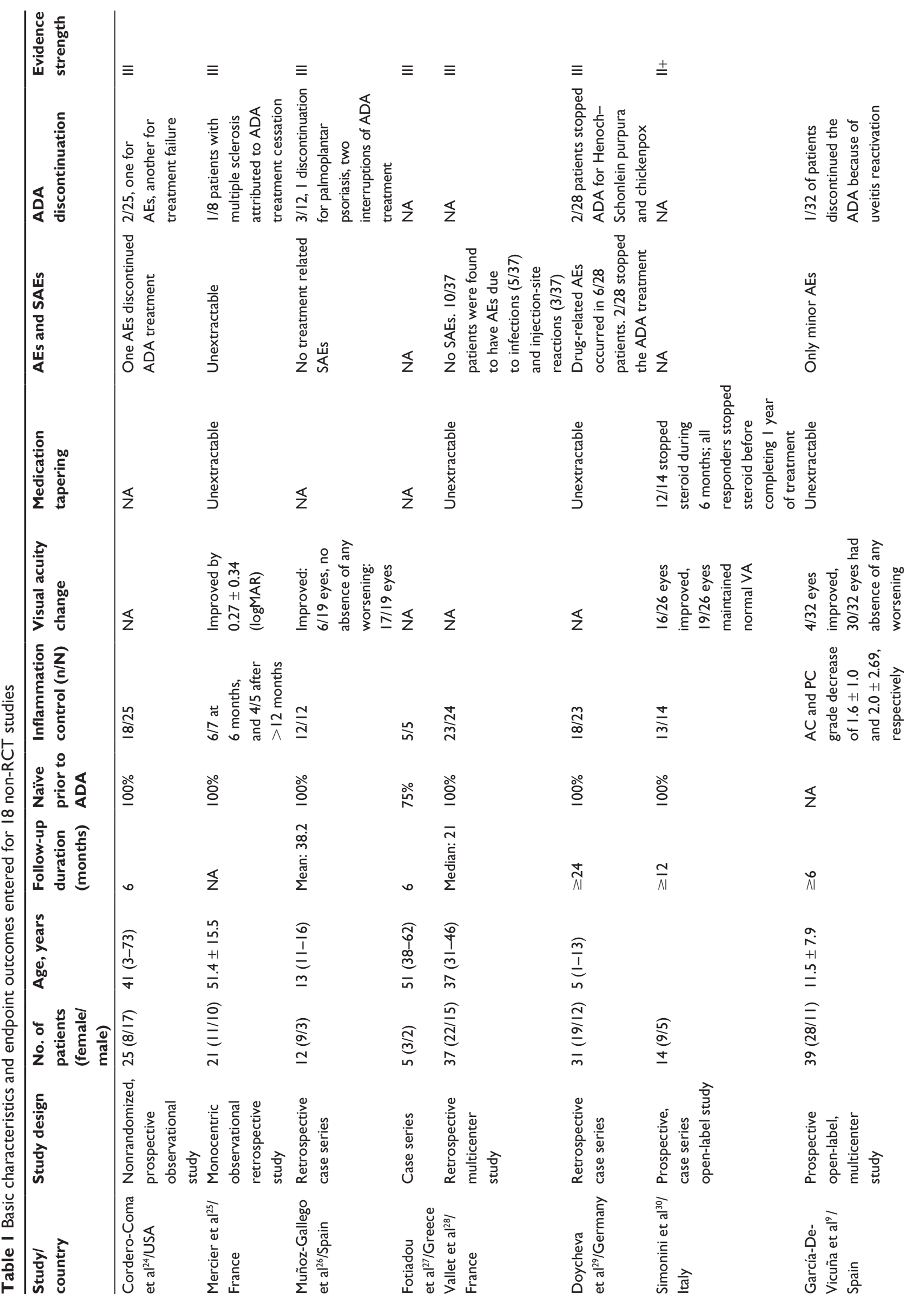



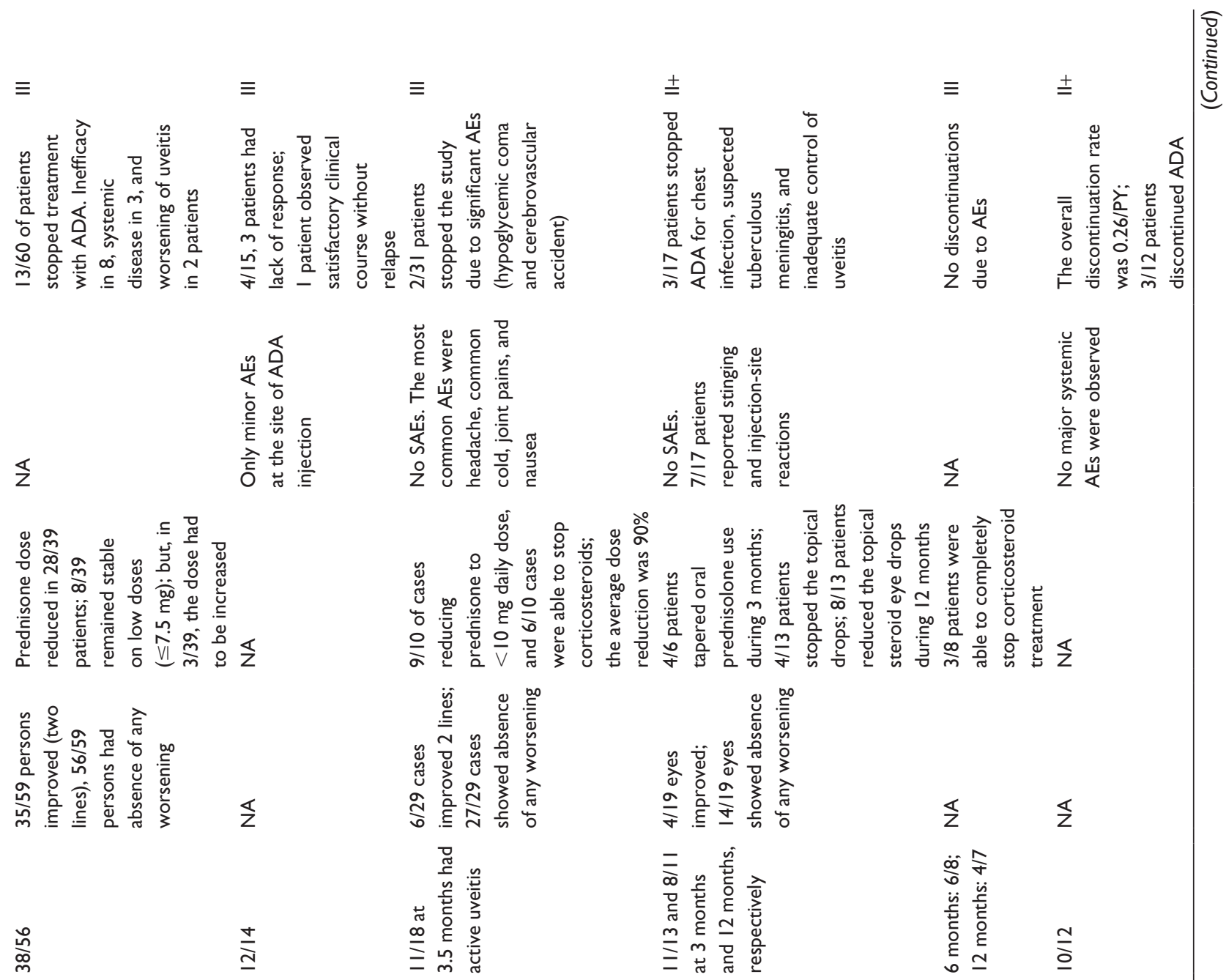

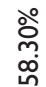

$\frac{\stackrel{0}{\circ}}{\infty}$

$\stackrel{\circ}{\circ}$
ஸnं

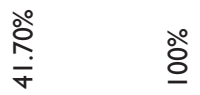

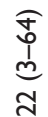

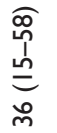

$\stackrel{\sim}{n}$

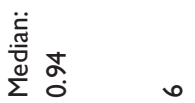

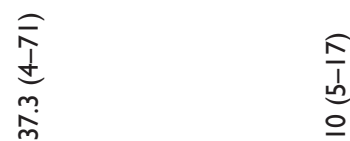

oे
0
dे
o.
के

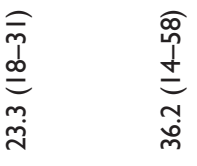

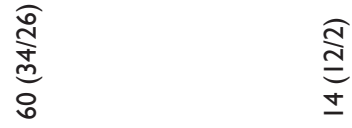

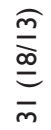

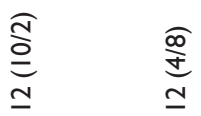
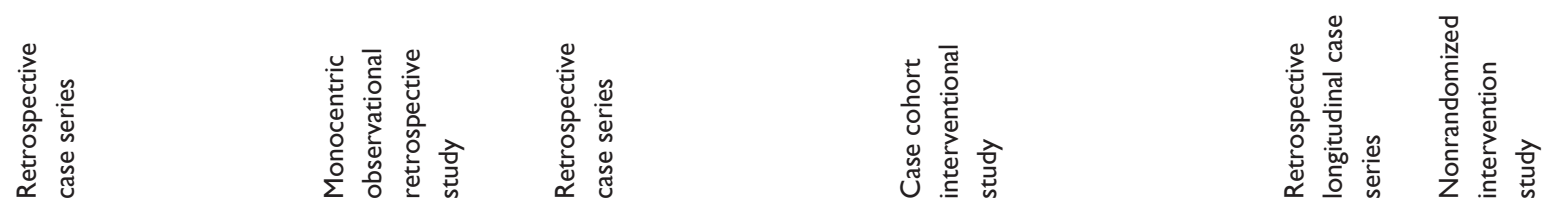

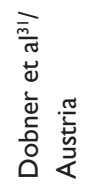

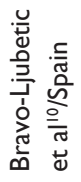

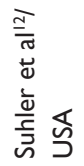

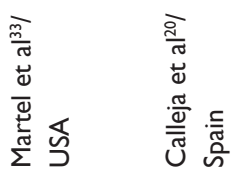




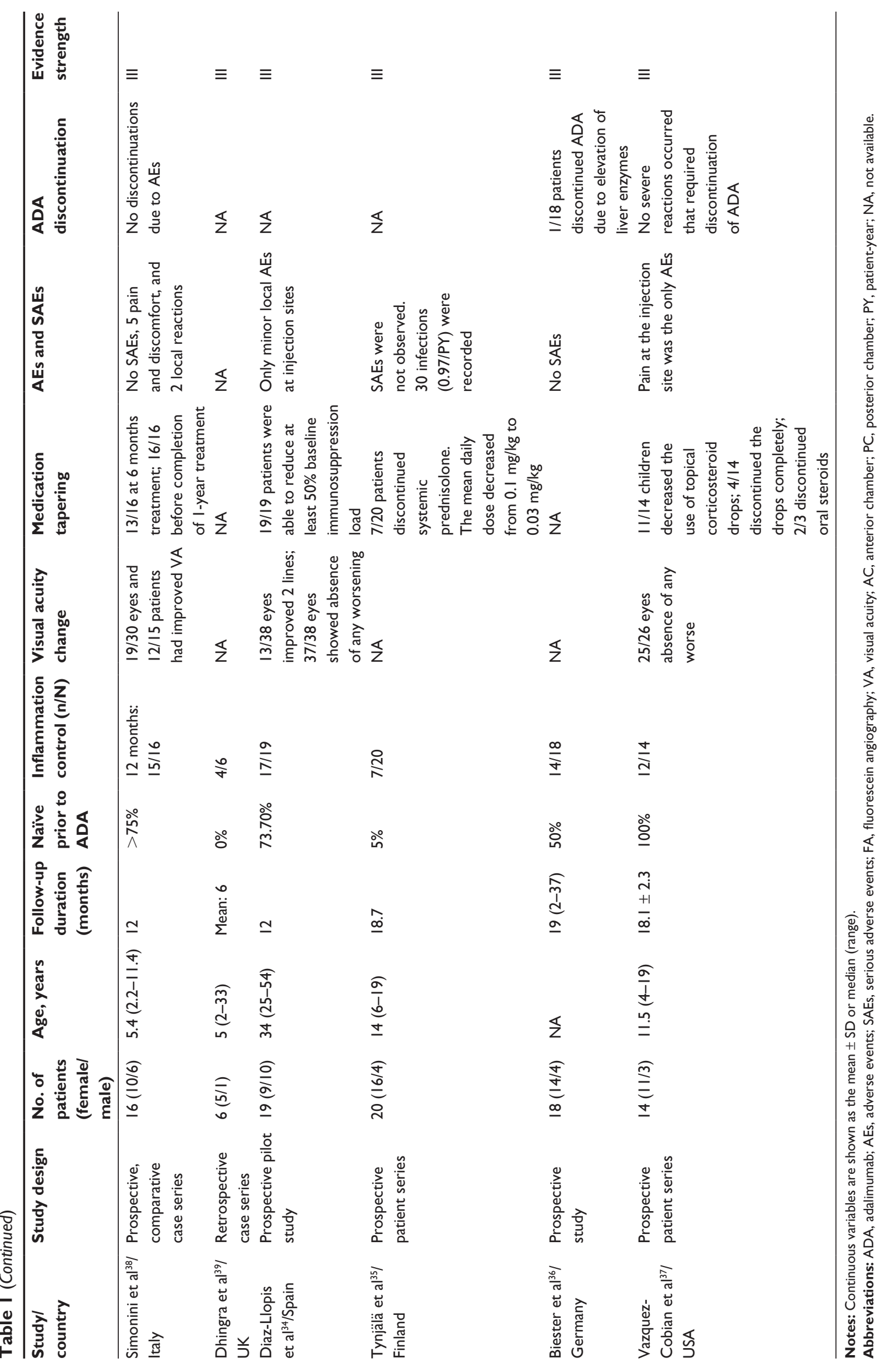


weight - every 2 weeks by subcutaneous injection. Ten studies $^{10,20,24-26,28-30,37,38}$ administered ADA as the absolute first-line anti-TNF $\alpha$ agent, whereas only $11.1 \%$ used ADA as first-line therapy in two studies..$^{35,39}$ Three studies ${ }^{20,30,32}$ had a $\mathrm{II}^{+}$evidence strength, and the other 17 studies had III strength according to the SIGN criteria.
Table 2 shows the summary characteristics of the three selected RCTs studies. ${ }^{40-42}$ Although the three RCTs adopted the same endpoint (time to treatment failure), it was inappropriate to consolidate the outcomes directly. Firstly, uveitis activity was “inactive" in Quan's patients. Even between the other two studies, choosing "active" uveitis at baseline, the

Table 2 Main summary of characteristics of the three selected RCTs

\begin{tabular}{|c|c|c|c|c|c|c|}
\hline Study & $\begin{array}{l}\text { No (ADA/ } \\
\text { placebo) }\end{array}$ & $\begin{array}{l}\text { Active or inactive } \\
\text { in enrollment }\end{array}$ & Trial regimen & Outcome definition & Safety and comments & $\begin{array}{l}\text { Quality } \\
\text { score }\end{array}$ \\
\hline $\begin{array}{l}\text { Ramanan } \\
\text { et } \mathrm{al}^{40}\end{array}$ & $90(60 / 30,2: 1)$ & $\begin{array}{l}\text { Active: anterior } \\
\text { chamber grade } \geq I+ \\
\text { during the preceding } \\
12 \text { weeks of therapy }\end{array}$ & $\begin{array}{l}\text { MTX for all } \\
\text { with no dose } \\
\text { reduction or } \\
\text { change, ADA vs } \\
\text { placebo }\end{array}$ & $\begin{array}{l}\text { Over a period of two consecutive } \\
\text { visits, SUN cell-activity score } \\
\text { I) had a 2-grade increase, or } \\
\text { 2) had no change when the } \\
\text { entry grade of } \geq 3 \text {, or } 3 \text { ) had a } \\
\text { decrease of I grade or no change } \\
\text { with development of another } \\
\text { ocular coexisting condition, or } \\
\text { 4) still presented after } 6 \text { months } \\
\text { of therapy when the entry } \\
\text { grade was I or } 2 \text {, or } 5 \text { ) had } \\
\text { the worsening of an existing } \\
\text { ocular coexisting condition } \\
\text { after } 3 \text { months, or } 6 \text { ) the } \\
\text { use of ineligible concomitant } \\
\text { medications, or } 7 \text { ) the } \\
\text { intermittent of trial regimen } \\
\text { for } 4 \text { weeks cumulatively }\end{array}$ & $\begin{array}{l}\text { ADA group: } 58.4 \text { follow-up } \\
\text { person-years, } 588 \text { events } \\
\text { of any AEs, I } 7 \text { events of } \\
\text { serious AEs; placebo group: } \\
\text { I5.8 follow-up person- } \\
\text { years, } 103 \text { events of any AE, } \\
3 \text { events of serious AEs }\end{array}$ & 6 \\
\hline Jaffe et $\mathrm{al}^{42}$ & $217(110 / 107,1: 1)$ & $\begin{array}{l}\text { Active: anterior } \\
\text { chamber or vitreous } \\
\text { haze grade } \geq 2+\text { with } \\
\text { preceding } \geq 2 \text { weeks } \\
\text { of therapy }\end{array}$ & $\begin{array}{l}\text { Prednisone burst } \\
\text { for all at Week } 0 \text {, } \\
\text { tapering to } 0 \text { by } \\
\text { Week I5. ADA } \\
\text { vs placebo }\end{array}$ & $\begin{array}{l}\text { I) New inflammatory lesion } \\
\text { relative to baseline, or } \\
2 \text { ) a decrease to } \leq 0.5+\text { at week } 6 \\
\text { or a } 2 \text {-step increase in anterior } \\
\text { chamber cell or vitreous haze } \\
\text { grade, or } 3 \text { ) worsening of BCVA } \\
\text { by } \geq I 5 \text { letters relative to the } \\
\text { best state previously achieved }\end{array}$ & $\begin{array}{l}\text { ADA group: } 62.5 \text { follow-up } \\
\text { person-years, } 657 \text { events } \\
\text { of any AEs, I } 6 \text { I events of } \\
\text { any AEs related to trial } \\
\text { intervention, I } 8 \text { events } \\
\text { of SAEs, } 6 \text { events of } \\
\text { SAEs related to trial } \\
\text { intervention; I } 3 \text { AEs } \\
\text { leading to discontinuation } \\
\text { of ADA. Placebo group: } \\
44.3 \text { follow-up person- } \\
\text { years, } 430 \text { events of any } \\
\text { AEs, } 55 \text { events of any AEs } \\
\text { related to trial intervention, } \\
6 \text { events of SAEs, } 3 \text { events } \\
\text { of SAEs related to trial } \\
\text { intervention; } 5 \text { AEs leading } \\
\text { to discontinuation of ADA }\end{array}$ & 7 \\
\hline $\begin{array}{l}\text { Nguyen } \\
\text { et } \mathrm{al}^{41}\end{array}$ & $225(I \mid 4 / I I I, I: I)$ & $\begin{array}{l}\text { Inactive: anterior } \\
\text { chamber cell grade/ } \\
\text { vitreous haze grade } \\
\text { of } 0.5+\text { or less }\end{array}$ & $\begin{array}{l}\text { Prednisone burst } \\
\text { for all at Week } 0 \text {, } \\
\text { tapering to } 0 \text { by } \\
\text { Week 19. ADA } \\
\text { vs placebo }\end{array}$ & $\begin{array}{l}\text { I) New active inflammatory } \\
\text { chorioretinal or retinal vascular } \\
\text { lesions, or } 2 \text { ) worsening of BCVA } \\
\text { by } \geq 15 \text { letters, or } 3 \text { ) a } 2 \text {-step } \\
\text { increase in anterior chamber cell } \\
\text { or vitreous haze grade relative to } \\
\text { baseline }\end{array}$ & $\begin{array}{l}\text { ADA group: } 94.5 \text { follow-up } \\
\text { person-years, } 83 \text { I events of } \\
\text { any AEs, I } 3 \text { events of SAEs; } \\
\text { I I events of AEs leading to } \\
\text { cessation of ADA. Placebo } \\
\text { group: } 7 \text { I. } 0 \text { person-years, } \\
642 \text { events of any AEs, } \\
\text { I0 events of SAEs; } 7 \text { events } \\
\text { of AEs leading to ADA } \\
\text { discontinuation }\end{array}$ & 7 \\
\hline
\end{tabular}

Abbreviations: RCT, randomized clinical trial; ADA, adalimumab; MTX, methotrexate; SUN, Standardization of Uveitis Nomenclature; BCVA, best-corrected visual acuity; $A E s$, adverse events; SAEs, serious adverse effects. 
definition of "active" was different for the anterior chamber grade (Grade $\geq 1$ in Jaffe et $\mathrm{al}^{42}$ vs Grade $\geq 2$ in Ramanan et al). Nonetheless, Ramanan et al designed the trial regimen as an ADA plus methotrexate (MTX), compared to ADA alone in the other two studies, and adopted different outcome definitions as well.

All three RCTs that were included reported methods of sequence generation and allocation concealment in detail. Furthermore, blinding was at least mentioned in the method description. The mean Jadad score was 6.7 (high quality).

\section{Control of uveitis activity}

A total of 18 studies showed controlled activity matching our criteria, of which four ${ }^{20,24,27,39}$ contained information of follow-up time $\leq 6$ months; 11 studies ${ }^{10,26,28-31,34-38}$ contained information of follow-up time $\geq 12$ months; and four ${ }^{12,25,32,33}$ contained both. An additional Study ${ }^{9}$ reported mean activity grade change (1.6 \pm 1.0 for AC) before and after application of ADA, but was excluded from further analysis.

Figure 2 shows the pooled proportion results of controlled uveitis activity in a meta-analysis. When the follow-up duration was $\leq 6$ months, the pooled controlled activity proportion was $74 \%$ (95\% CI $64 \%-82 \%)$, with no statistically significant difference $\left(\chi^{2}=0.920, p=0.337\right)$ compared to a follow-up duration of $\geq 12$ months (79\%, 95\% CI 69\%-87\%). With obvious heterogeneity in the combination of proportions with follow-up $\geq 12$ months $\left(I^{2}=57 \%, p<0.01\right)$, a subgroup analysis was conducted by dividing studies into "almost naïve", "partly naïve", and "hardly naïve" according to anti-TNF $\alpha$ agent usage prior to ADA treatment. Figure 3 shows that, when ADA was used as the first-line anti-TNF $\alpha$ agent, the pooled proportion of activity control reached the highest value $(87 \%, 95 \%$ CI 80\%-92\%). The improvement proportion revealed a decreasing trend (Cochran-Armitage Trend Test: $Z=-5.277, p<0.001)$ in the three subgroups of "almost naïve", "partly naïve", and "hardly naive". Heterogeneity was well resolved after subgroup analysis.

\section{Treatment failure}

Despite different designs, all three RCTs reported that the time to treatment failure in the ADA groups was two- to threefold long compared to that in the placebo groups. Patients who received ADA were significantly less likely to have treatment failure than those who received placebo, regardless of whether they were treated concomitantly with MTX. The HR ranging from 0.25 to $0.57(p<0.05)$ showed that ADA delayed treatment failure in nearly $50 \%-75 \%$ patients, especially when ADA was used concomitantly with MTX $(H R=0.25)$. Differing with the other two studies, Nguyen et $\mathrm{al}^{41}$ reported that, although numerically lower in the ADA group, the treatment-failure risk caused by new lesions and increase in anterior chamber cells/vitreous haze grade did not significantly differ between the ADA and placebo groups (Table 3).

\section{Visual acuity}

A total of 10 studies $^{9,12,25,26,30-32,34,37,38}$ reported VA outcomes. Improvement of VA occurred in 52 (41.3\%) of 126 eyes, with VA increasing by three or more lines in five studies; $9,26,30,32,38$ in $53(51.5 \%)$ of the 103 patients, VA increased by two lines in three studies. ${ }^{12,31,38}$ The proportion of VA remaining stable or improving at least one line reached $88.8 \%(142 / 160)$ in the involved eyes ${ }^{9,26,30,32,34,37}$ and in $94.3 \%(83 / 88)^{12,31}$ of the patients. VA worsened in $11.2 \%$ of the eyes and $5.7 \%$ of the patients during ADA treatment. Mercier et $\mathrm{al}^{25}$ reported significantly improved VA by a logMAR decrease $(0.27 \pm 0.34)$ on ADA treatment. When determined by worsening VA, $\mathrm{RCTs}^{41,42}$ showed that ADA treatment could reduce treatment failure by $43 \%-67 \%$.

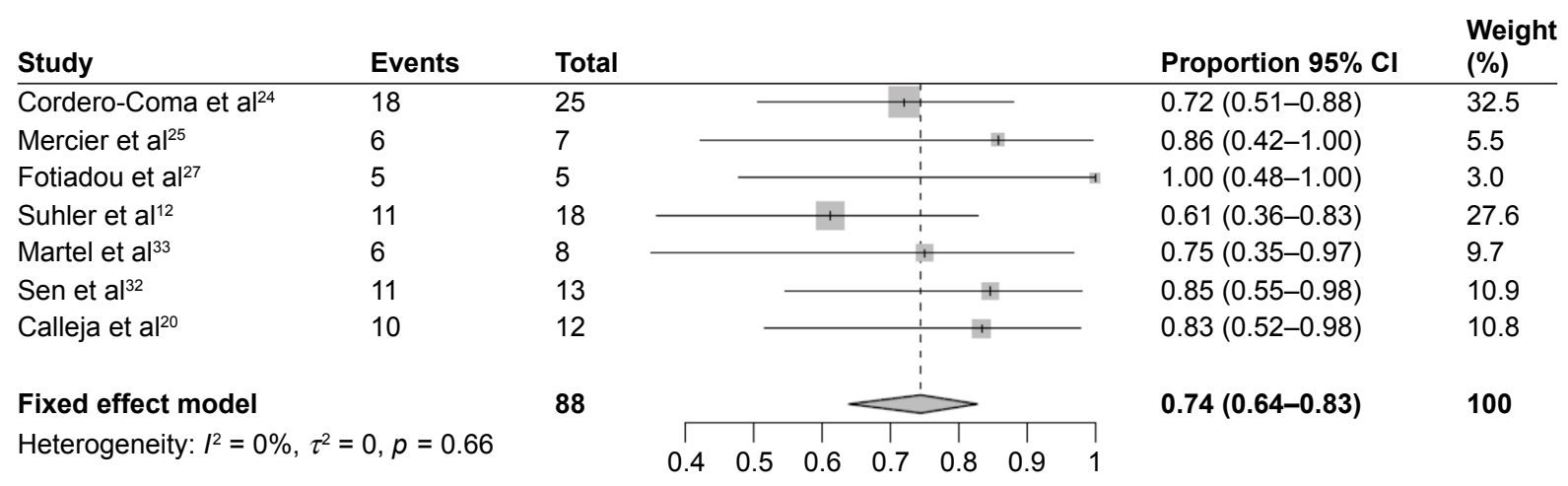

Figure 2 The pooled proportion of uveitis activity control with a follow-up duration of $\leq 6$ months. 


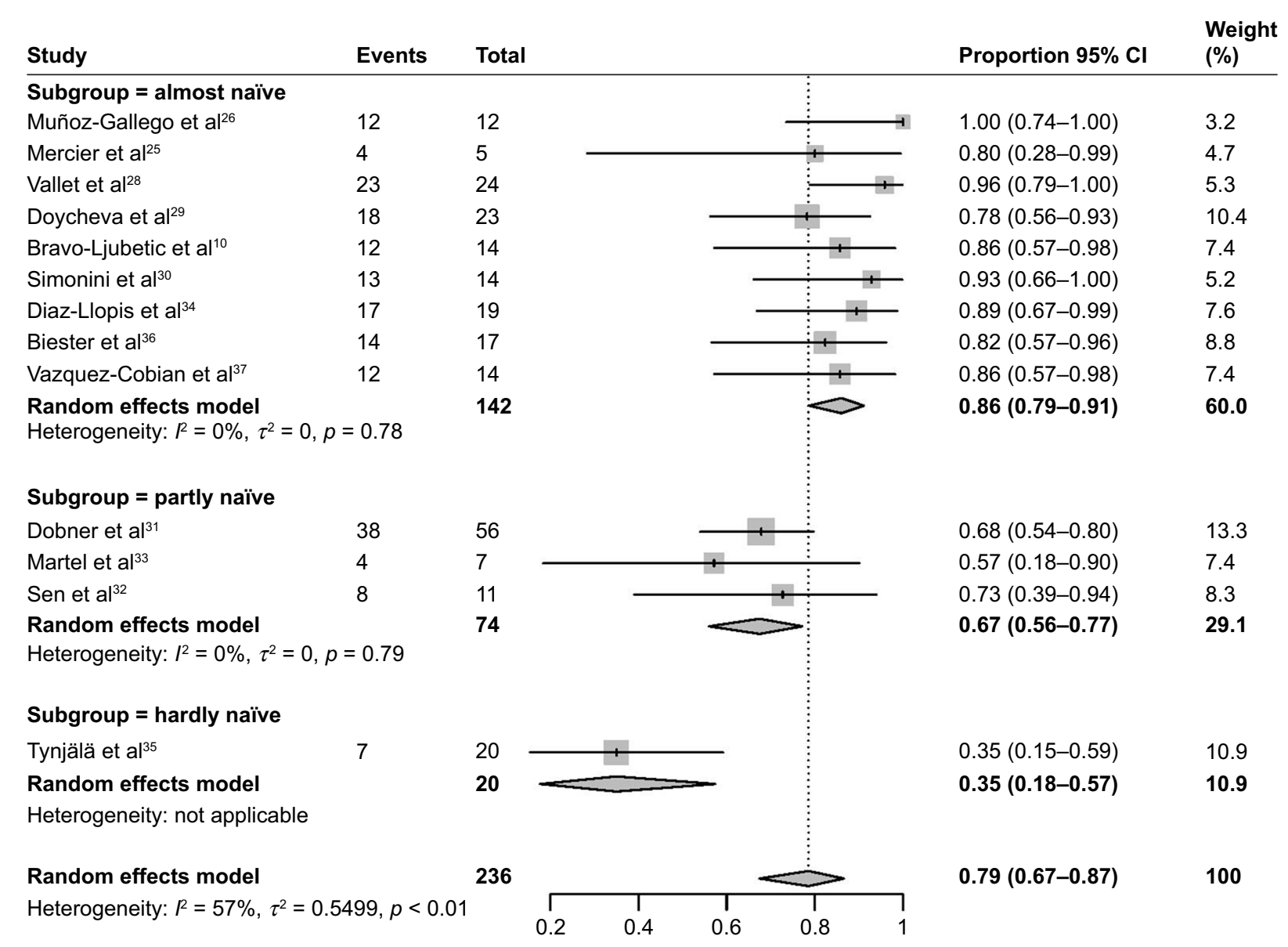

Figure 3 The pooled proportion of controlled uveitis activity and subgroup analysis when the follow-up duration $\geq 12$ months. "Almost naïve" means patients were mainly (>70\%) anti-TNF $\alpha$ naïve before ADA treatment; partly naïve means half $(50 \% \pm 10 \%)$ of the patients were anti-TNF $\alpha$ naïve; hardly naïve means less than $30 \%$ of patients were anti-TNF $\alpha$ naïve. Heterogeneity disappeared when analyzed by subgroups.

Abbreviation: ADA, adalimumab.

\section{Corticosteroid sparing}

Information on corticosteroid sparing was extractable in nine of the 20 non-RCT articles. Forty (48.8\%) of the 82 patients ${ }^{12,30,32,33,35,37}$ with ADA treatment completely discontinued corticosteroid, indicating a moderate improvement in the corticosteroid-sparing effect. Six studies ${ }^{12,31,32,34,37,38}$ reported tapering of corticosteroid administration in 91 $(82.0 \%)$ of the 111 patients. A quantitative analysis ${ }^{12}$ showed that the average dose was reduced by $90 \%$ (from 31 to $3 \mathrm{mg}$ ) from the pretreatment visit to the end of ADA medication.

Table 3 Summary of ADA efficacy on the treatment of non-infectious uveitis in three selected RCTs

\begin{tabular}{|c|c|c|c|c|}
\hline Study & $\begin{array}{l}\text { Endpoint \& } \\
\text { components }\end{array}$ & $\begin{array}{l}\text { Time to treatment } \\
\text { failure (ADA vs placebo) }\end{array}$ & HR (95\% CI) & $p$-value \\
\hline \multirow[t]{2}{*}{ Ramanan et $\mathrm{al}^{40}$} & Total effect & $>18$ vs 6.0 months & $0.25(0.12-0.49)$ & $<0.001$ \\
\hline & Anterior chamber cells & & $0.25(0.12-0.49)$ & $<0.001$ \\
\hline \multirow[t]{5}{*}{ Jeff J et $\mathrm{al}^{42}$} & Total effect & 6 vs 3.3 months & $0.50(0.36-0.70)$ & $<0.001$ \\
\hline & Vitreous haze & & $0.32(0.18-0.58)$ & $<0.001$ \\
\hline & New lesions & & $0.38(0.21-0.69)$ & 0.001 \\
\hline & Anterior chamber cells & & $0.51(0.3-0.86)$ & 0.010 \\
\hline & BCVA & & $0.56(0.32-0.98)$ & 0.040 \\
\hline \multirow[t]{5}{*}{ Nguyen et $\mathrm{al}^{41}$} & Total effect & $>18$ vs 8.3 months & $0.57(0.39-0.84)$ & 0.004 \\
\hline & Vitreous haze & & $0.79(0.34-1.18)$ & 0.589 \\
\hline & New lesions & & $0.55(0.26-1.15)$ & 0.105 \\
\hline & Anterior chamber cells & & $0.70(0.42-1.18)$ & 0.180 \\
\hline & BCVA & & $0.33(0.16-0.70)$ & 0.002 \\
\hline
\end{tabular}

Abbreviations: RCT, randomized clinical trial; ADA, adalimumab; BCVA, best-corrected visual acuity. 
Similarly, García-De-Vicuña et $\mathrm{al}^{9}$ found that the mean daily dose of prednisolone was successfully decreased from $0.1 \mathrm{mg} / \mathrm{kg}$ to $0.03 \mathrm{mg} / \mathrm{kg}$. Details are shown in Table 2 .

\section{Safety}

A total of 14 case-series studies and three RCTs had safety information on ADA treatment. According to the available case-series data, 30 patients (30.6\%) experienced AEs. ${ }^{6,29,32,38}$ However, 12 of the case series explicitly reported that only minor drug-related AEs were observed. In the three RCTs, the incidence of AEs per patient-year was 9.6 events $(2,076$ events in 215.4 follow-up patient-years). The corresponding incidence of SAEs was 0.22 events (48 events in the same follow-up years). The incidences of both $\mathrm{AE}$ and SAEs were numerically higher than those in the placebo groups (9.0 events and 0.14 events per patient-year, corresponding to 1,175 events and 19 events in 131.1 patient-years, respectively). Jaffe et $\mathrm{l}^{42}$ reported that the incidences of ADA treatment-related AEs and SAEs were 2.6 and 0.1 events per patient-year, respectively. The most frequently reported AEs were injection-site reactions and allergic reactions.

\section{Discontinuation of ADA}

Discontinuation of ADA was reported in 14 case-series studies and two RCTs. In 11 case-series studies, ADA treatment was discontinued in 32 patients (11.6\%), $9,10,12,20,24-26,29,31-33,36-38$ of which 16 patients (6.2\%) discontinued ADA for uncontrolled or worsening of uveitis activity and six $(2.3 \%)$ discontinued because of AEs. In the two RCTs, ${ }^{41,42}$ the incidence of AEs that induced ADA discontinuation was 0.15 events per patient-year (24 events in 157.0 follow-up patient-years).

\section{Discussion}

In our study, many aspects of the efficacy of ADA in uveitis were systematically reviewed including control of inflammation, improvement of VA, and AEs. The presented evidences were collected from RCTs and non-RCTs with different evidence strengths to provide more comprehensive analysis.

We categorized endpoints, for the first time, to two subgroups according to follow-up duration ( $\leq 6$ and $\geq 12$ months) to examine the short-term and relatively long-term efficacy on inflammation control. The inflammatory activity of uveitis was found to have improved by $74 \%$ and $79 \%$ in our combined analysis of short- and relatively long-term follow-up periods, respectively, which suggested that a stable efficacy can be achieved. In the $\geq 12$-month group, a subgroup of anti-TNF $\alpha$-naïve patients showed $86 \%$ improvement in uveitis activity with ADA treatment.
Furthermore, Simonini et al ${ }^{43}$ published a long-period follow-up ( $\geq 12$ months) efficacy of ADA in childhood chronic JIA uveitis which was anti-TNF $\alpha$ naïve. Their result of $87 \%$ was consistent with our results $(p=0.884)$. Comparatively, our study contained data from more studies, larger sample size (142 vs 31), wider range of age, and broader diversity of uveitis and, therefore, might have a better population representation. Additionally, we found that being naïve to anti-TNF $\alpha$ agents might affect the efficacy of ADA. The results supported the recommendation of ADA as the first-line choice for corticosteroid-sparing therapy for several types of uveitis. ${ }^{44}$ Another review, ${ }^{45}$ extracting a small number of cases, reported that ADA was effective with an accumulated crude response rate of $70.6 \%(24 / 34)$, even when used after a previous course of anti-TNF $\alpha$ agents that failed to maintain remission in pediatric autoimmune chronic uveitis. However, in our analysis of all ages, a lower efficacy was found when ADA was used or partly used after treatment with another anti-TNF $\alpha$ agent. In a JIA-associated refectory uveitis cohort, ${ }^{35}$ improved ADA activity was found in $35 \%$ of patients. Patients with favorable responses were younger at the baseline. Further studies or analysis are still needed to illustrate this difference.

Besides effectiveness in achieving improvement in the eyes with active uveitis, several promising results have contributed to the reasonable use of ADA in clinical treatment. 1) ADA can effectively control the worsening of VA $(88.8 \%$ involved eyes in our analysis). One third of eyes received VA improvement according to the SUN standard criteria. ${ }^{21}$ Structural damage that was already present before ADA therapy might be one reason for the decrease in VA in some eyes. ${ }^{26}$ 2) Good corticosteroid-sparing effect. An average of three quarters of the patients significantly reduced corticosteroid use, and nearly half of the patients successfully discontinued corticosteroid use during ADA treatment. Such an effect avoided AEs induced by corticosteroids during uveitis activity control. 3) ADA was generally well tolerated in the treatment of non-infectious uveitis. Most real-world studies only observed minor drug-related AEs. The observed AE profiles were similar to the known safety aspects of ADA use.

Considering the complexity of outcome reporting in the literature, we chose improvement in inflammatory activity as the primary and compulsive outcome. Zannin et al ${ }^{17}$ reported the 1-year follow-up of a large cohort of 43 JIA-uveitis patients treated with ADA and similarly concluded that ADA was effective, with a remission rate of $67.4 \%$. We excluded the study because "remission", defined as absence of active 
uveitis for more than 6 months on systemic treatment, was different from our primary outcome. Díaz-Llopis et a ${ }^{46}$ found a marked decrease of anterior chamber degree from 1.51 to 0.25 after ADA treatment in 131 uveitis patients. Similarly, another case series ${ }^{9}$ with 39 JIA-uveitis children found the anterior chamber degree to have decreased significantly from 2.02 to 0.42 . We excluded them because a dichotomous outcome was not extractable.

ADA's efficacy in the treatment of uveitis pooled by case series might appear less persuasive because of an inherent low evidence strength. However, an expert panel recommendation ${ }^{44}$ was published in 2014 and accepted ADA as the first- or second-line immunomodulatory agent in treating uveitis based on evidence from case studies. The three RCT studies, ${ }^{40-42}$ although a limited number, further confirmed such an efficacy that indicated ADA delayed the time of treatment failure few-fold and greatly reduced the risk of disease recurrence as compared to placebo. Conservatively speaking, because of the unique characteristics of uveitis, many facets of clinical data still have not reached consensus. ${ }^{44}$ More high-quality, large-scale RCTs designed with uniform inclusion criteria and recognized endpoints are required.

\section{Limitations}

First, some included studies ${ }^{24-31}$ had various uveitis etiologies such as JIA, Behçet's disease, and HLA-B27-associated uveitis. Subgroup analysis according to underling disease was not conducted because the data were unextractable. Clinical physicians might be interested in ADA efficacy for uveitis of different etiologies. Second, the proportion of VA improvement, ADA discontinuation, corticosteroid sparing, and observed AEs were simply analyzed by averages without considering the weight of each study. In view of the fact that most studies used for analysis only had evidence strengths of SIGN levels II and III, a dialectic point of view is still needed when referring to these results.

\section{Conclusion}

This systematic review and meta-analysis revealed the overall efficacy of ADA in treating non-infectious uveitis and found it was well received for its potent control of inflammatory activity in short- and long-term follow-up durations, moderately high VA improvement, relatively low AE/SAEs, and good corticosteroid-sparing effect. The efficacy was positively determined by RCTs. More high-quality, largescale clinical trials with similar design are needed to further prove the conclusion with stronger evidence.

\section{Acknowledgments}

This study is supported by the National Natural Science Foundation of China (grant nos. 81470621 and 81770949), Henan Science and Technology Bureau (grant no. 182102310145), National Key Clinical Specialties Construction Program of China, and Henan Key Laboratory of Ophthalmology and Visual Science.

\section{Author contributions}

Shuai Ming: data collection, analysis, manuscript writing. Bo Lei: protocol/project development, paper revising. All authors contributed toward data analysis, drafting and revising the paper and agree to be accountable for all aspects of the work.

\section{Disclosure}

The authors report no conflicts of interest in this work.

\section{References}

1. Airody A, Heath G, Lightman S, Gale R. Non-infectious uveitis: optimising the therapeutic response. Drugs. 2016;76(1):27-39.

2. Schwartzman S, Schwartzman M. The use of biologic therapies in uveitis. Clin Rev Allergy Immunol. 2015;49(3):307-316.

3. Nussenblatt RB. The natural history of uveitis. Int Ophthalmol. 1990;14(5-6):303-308

4. Burmester GR, Panaccione R, Gordon KB, McIlraith MJ, Lacerda AP Adalimumab: long-term safety in 23458 patients from global clinical trials in rheumatoid arthritis, juvenile idiopathic arthritis, ankylosing spondylitis, psoriatic arthritis, psoriasis and Crohn's disease. Ann Rheum Dis. 2013;72(4):517-524.

5. Balevic SJ, Rabinovich CE. Profile of adalimumab and its potential in the treatment of uveitis. Drug Des Devel Ther. 2016;10:2997-3003. eCollection 2016.

6. Vallet H, Seve P, Biard L, et al; French Uveitis Network. Infliximab versus adalimumab in the treatment of refractory inflammatory uveitis: a multicenter study from the French Uveitis Network. Arthritis Rheumatol. 2016;68(6):1522-1530.

7. Durrani K, Kempen JH, Ying GS, et al. Adalimumab for ocular inflammation. Ocul Immunol Inflamm. 2016:1-8.

8. Interlandi E, Leccese P, Olivieri I, Latanza L. Adalimumab for treatment of severe Behçet's uveitis: a retrospective long-term follow-up study. Clin Exp Rheumatol. 2014;32(4 Suppl 84):S58-S62.

9. García-De-Vicuña C, Díaz-Llopis M, Salom D, et al. Usefulness of adalimumab in the treatment of refractory uveitis associated with juvenile idiopathic arthritis. Mediators Inflamm. 2013;2013: 560632.

10. Bravo-Ljubetic L, Peralta-Calvo J, Noval S, Pastora-Salvador N, Abelairas-Gómez J, Merino R. Adalimumab therapy for refractory childhood uveitis. J AAPOS. 2013;17(5):456-459.

11. Magli A, Forte R, Navarro P, et al. Adalimumab for juvenile idiopathic arthritis-associated uveitis. Graefes Arch Clin Exp Ophthalmol. 2013;251(6):1601-1606.

12. Suhler EB, Lowder CY, Goldstein DA, et al. Adalimumab therapy for refractory uveitis: results of a multicentre, open-label, prospective trial. Br J Ophthalmol. 2013;97(4):481-486.

13. Rudwaleit M, Rødevand E, Holck P, et al. Adalimumab effectively reduces the rate of anterior uveitis flares in patients with active ankylosing spondylitis: results of a prospective open-label study. Ann Rheum Dis. 2009;68(5):696-701. 
14. Erckens RJ, Mostard RL, Wijnen PA, Schouten JS, Drent M. Adalimumab successful in sarcoidosis patients with refractory chronic noninfectious uveitis. Graefes Arch Clin Exp Ophthalmol. 2012;250(5): 713-720.

15. Kotaniemi K, Säilä H, Kautiainen H. Long-term efficacy of adalimumab in the treatment of uveitis associated with juvenile idiopathic arthritis. Clin Ophthalmol. 2011;5:1425-1429.

16. Gallagher M, Quinones K, Cervantes-Castañeda RA, Yilmaz T, Foster CS. Biological response modifier therapy for refractory childhood uveitis. Br J Ophthalmol. 2007;91(10):1341-1344.

17. Zannin ME, Birolo C, Gerloni VM, et al. Safety and efficacy of infliximab and adalimumab for refractory uveitis in juvenile idiopathic arthritis: 1-year followup data from the Italian Registry. J Rheumatol. 2013;40(1):74-79.

18. Bou R, Adán A, Borrás F, et al. Clinical management algorithm of uveitis associated with juvenile idiopathic arthritis: interdisciplinary panel consensus. Rheumatol Int. 2015;35(5):777-785.

19. LaMattina KC, Goldstein DA. Adalimumab for the treatment of uveitis. Expert Rev Clin Immunol. 2017;13(3):181-188.

20. Calleja S, Cordero-Coma M, Rodriguez E, Llorente M, Franco M, Ruiz de Morales JG. Adalimumab specifically induces CD3(+) CD4(+) CD25(high) Foxp3(+) CD127(-) T-regulatory cells and decreases vascular endothelial growth factor plasma levels in refractory immunomediated uveitis: a non-randomized pilot intervention study. Eye (Lond). 2012;26(3):468-477.

21. Jabs DA, Nussenblatt RB, Rosenbaum JT; Standardization of Uveitis Nomenclature (SUN) Working Group. Standardization of uveitis nomenclature for reporting clinical data. Results of the First International Workshop. Am J Ophthalmol. 2005;140(3):509-516.

22. Keaney M, Lorimer AR. Auditing the implementation of SIGN (Scottish Intercollegiate Guidelines Network) clinical guidelines. Int J Health Care Qual Assur Inc Leadersh Health Serv. 1999;12(6-7):314-317.

23. Moher D, Liberati A, Tetzlaff J, Altman DG; PRISMA Group. Preferred reporting items for systematic reviews and meta-analyses: the PRISMA Statement. Open Med. 2009;3(3):e123-e130.

24. Cordero-Coma M, Calleja-Antolín S, Garzo-García I, et al. Adalimumab for treatment of noninfectious uveitis: immunogenicity and clinical relevance of measuring serum drug levels and antidrug antibodies. Ophthalmology. 2016;123(12):2618-2625.

25. Mercier AE, Ribeiro E, Korobelnik JF, Delyfer MN, Rougier MB. Efficacy of anti-TNF- $\alpha$ therapy for the treatment of non-infectious uveitis: a retrospective study of 21 patients. Ocul Immunol Inflamm. 2016:1-8.

26. Muñoz-Gallego A, Barral E, Enríquez E, Tejada P, Barceló A, de Inocencio J. Adalimumab for the treatment of refractory noninfectious paediatric uveitis. Int Ophthalmol. 2017;37(3):719-725.

27. Fotiadou C, Lazaridou E, Kemanetzi C, Kyrmanidou E, Ioannides D. Recalcitrant psoriatic uveitis and anti-tumor necrosis factor- $\alpha$ monoclonal antibodies: experience from a psoriasis referral center. Int $J$ Dermatol. 2015;54(9):1105-1108.

28. Vallet H, Riviere S, Sanna A, et al; French Behçet Network. Efficacy of anti-TNF alpha in severe and/or refractory Behçet's disease: multicenter study of 124 patients. J Autoimmun. 2015;62:67-74.

29. Doycheva D, Zierhut M, Blumenstock G, et al. Immunomodulatory therapy with tumour necrosis factor alpha inhibitors in children with antinuclear antibody-associated chronic anterior uveitis: long-term results. Br J Ophthalmol. 2014;98(4):523-528.
30. Simonini G, Taddio A, Cattalini M, et al. Superior efficacy of adalimumab in treating childhood refractory chronic uveitis when used as first biologic modifier drug: adalimumab as starting anti-TNF- $\alpha$ therapy in childhood chronic uveitis. Pediatr Rheumatol Online J. 2013;11:16.

31. Dobner BC, Max R, Becker MD, et al. A three-centre experience with adalimumab for the treatment of non-infectious uveitis. $\mathrm{Br} J$ Ophthalmol. 2013;97(2):134-138.

32. Sen ES, Sharma S, Hinchcliffe A, Dick AD, Ramanan AV. Use of adalimumab in refractory non-infectious childhood chronic uveitis: efficacy in ocular disease - a case cohort interventional study. Rheumatology (Oxford). 2012;51(12):2199-2203.

33. Martel JN, Esterberg E, Nagpal A, Acharya NR. Infliximab and adalimumab for uveitis. Ocul Immunol Inflamm. 2012;20(1):18-26.

34. Diaz-Llopis M, García-Delpech S, Salom D, et al. Adalimumab therapy for refractory uveitis: a pilot study. J Ocul Pharmacol Ther. 2008;24(3):351-361.

35. Tynjälä $\mathrm{P}$, Kotaniemi $\mathrm{K}$, Lindahl $\mathrm{P}$, et al. Adalimumab in juvenile idiopathic arthritis-associated chronic anterior uveitis. Rheumatology (Oxford). 2008;47(3):339-344.

36. Biester S, Deuter C, Michels H, et al. Adalimumab in the therapy of uveitis in childhood. Br J Ophthalmol. 2007;91(3):319-324.

37. Vazquez-Cobian LB, Flynn T, Lehman TJ. Adalimumab therapy for childhood uveitis. J Pediatr. 2006;149(4):572-575.

38. Simonini G, Taddio A, Cattalini M, et al. Prevention of flare recurrences in childhood-refractory chronic uveitis: an open-label comparative study of adalimumab versus infliximab. Arthritis Care Res (Hoboken). 2011;63(4):612-618.

39. Dhingra N, Morgan J, Dick AD. Switching biologic agents for uveitis. Eye (Lond). 2009;23(9):1868-1870.

40. Ramanan AV, Dick AD, Jones AP, et al; SYCAMORE Study Group. Adalimumab plus methotrexate for uveitis in juvenile idiopathic arthritis. N Engl J Med. 2017;376(17):1637-1646.

41. Nguyen QD, Merrill PT, Jaffe GJ, et al. Adalimumab for prevention of uveitic flare in patients with inactive non-infectious uveitis controlled by corticosteroids (VISUAL II): a multicentre, doublemasked, randomised, placebo-controlled phase 3 trial. Lancet. 2016; 388(10050):1183-1192.

42. Jaffe GJ, Dick AD, Brézin AP, et al. Adalimumab in patients with active noninfectious uveitis. N Engl J Med. 2016;375(10):932-943.

43. Simonini G, Druce K, Cimaz R, Macfarlane GJ, Jones GT. Current evidence of anti-tumor necrosis factor $\alpha$ treatment efficacy in childhood chronic uveitis: a systematic review and meta-analysis approach of individual drugs. Arthritis Care Res (Hoboken). 2014;66(7):1073-1084.

44. Levy-Clarke G, Jabs DA, Read RW, Rosenbaum JT, Vitale A, Van Gelder RN. Expert panel recommendations for the use of anti-tumor necrosis factor biologic agents in patients with ocular inflammatory disorders. Ophthalmology. 2014;121(3):785.e3-796.e3.

45. Simonini G, Katie D, Cimaz R, Macfarlane GJ, Jones GT. Does switching anti-TNF $\alpha$ biologic agents represent an effective option in childhood chronic uveitis: the evidence from a systematic review and meta-analysis approach. Semin Arthritis Rheum. 2014;44(1):39-46.

46. Díaz-Llopis M, Salom D, Garcia-de-Vicuña C, et al. Treatment of refractory uveitis with adalimumab: a prospective multicenter study of 131 Patients. Ophthalmology. 2012;119(8):1575-1581.
Drug Design, Development and Therapy

\section{Publish your work in this journal}

Drug Design, Development and Therapy is an international, peerreviewed open-access journal that spans the spectrum of drug design and development through to clinical applications. Clinical outcomes, patient safety, and programs for the development and effective, safe, and sustained use of medicines are the features of the journal, which

\section{Dovepress}

has also been accepted for indexing on PubMed Central. The manuscript management system is completely online and includes a very quick and fair peer-review system, which is all easy to use. Visit http://www.dovepress.com/testimonials.php to read real quotes from published authors. 